\title{
A LEGITIMIDADE E LEGALIDADE DO CONSUMO DE DEFENSIVOS AGRÍCOLAS PIRATAS
}

\author{
Caroline Coradassi Almeida Santos ${ }^{1}$ \\ Luciano Ferreira de Lima $^{2}$ \\ Juliane Sachser Angnes ${ }^{3}$
}

\begin{abstract}
Resumo: Sobre o processo de comercialização de defensivos agrícolas, questiona-se a existência de aspectos de legitimidade em relação a produtos ilegais, contrabandeados e falsificados, também conhecidos ou chamados de piratas. O espirito deste estudo está baseado no questionamento anteriormente citado. Logo, alguns conceitos iniciais são necessários para a caracterização do tema. Assim, notavelmente, a origem da vida social e seus desdobramentos em diferentes relacionamentos, a partir de influências que culminaram para um desenvolvimento social, político e econômico se transformam a partir de propósitos e interesses. Nesse caso, permite-se dizer que a reflexão sobre o modo como as relações se estabelecem estão arraigadas às condições expostas diante dos grupos a qual pertencem, neste caso de estudo a rede de comercialização de defensivos agrícolas. A partir dos conceitos estudados criou-se um modelo, neste, em resumo, permite-se averiguar que as bases de governança e legitimidade influenciam de modo diferente toda a ação da rede e que se torna legítimo para os envolvidos a partir do momento que internalizam aquelas práticas e já não mais as questionam.
\end{abstract}

Palavras-chave: Produtos falsificados; legitimidade; legalidade.

\section{THE LEGITIMACY AND LEGALITY OF THE CONSUMPTION OF PIRATE AGRICULTURAL DEFENSIVES}

\begin{abstract}
Regarding the commercialization of pesticides, there are questions about the legitimacy of illegal, smuggled and falsified products, also known as pirates. The spirit of this study is based on the previously cited question. Therefore, some initial concepts are necessary for the characterization of the theme. Thus, remarkably, the origin of social life and its unfolding in different relationships, from influences that culminated in social, political and economic development, are transformed from purposes and interests. In this case, it is possible to say that the reflection on the way in which the relations are established are rooted in the conditions exposed before the groups to which they belong, in this case study the network of commercialization of agricultural pesticides. Based on the concepts studied, a model was created, in this, in a nutshell, it is possible to verify that the bases of governance and legitimacy influence in a different way all the action of the network and that becomes legitimate for those involved from the moment they internalize those practices and no longer question them.
\end{abstract}

Keywords: Counterfeit products; legitimacy; legality.

\section{LA LEGITIMIDAD Y LA LEGALIDAD DEL CONSUMO DE DEFENSA AGRÍCOLA PIRATA}

Resumen: Sobre el proceso de comercialización de defensivos agrícolas, se cuestiona la existencia de aspectos de legitimidad en relación a productos ilegales, contrabandeados y falsificados, también conocidos o llamados piratas. El espíritu de este estudio está basado en el cuestionamiento anteriormente citado. Por lo tanto, algunos conceptos iniciales son necesarios para la caracterización del tema. Así, notablemente, el origen de la vida social y sus desdoblamientos en diferentes relaciones, a partir de influencias que culminaron para un desarrollo social, político y económico se transforman a partir de propósitos e intereses. En este caso, se permite decir que la reflexión sobre el modo en que las relaciones se establecen están arraigadas a las condiciones expuestas ante los grupos a los que pertenecen, en este caso de estudio la red de comercialización de defensivos agrícolas. A partir de los conceptos estudiados se creó un modelo, en este, en resumen, se permite averiguar que las bases de gobernanza y legitimidad influencian de modo diferente toda la acción de la red y que se vuelve legítima para los involucrados a partir del momento que internalizan las prácticas y ya no las cuestionan.

Palabras clave: Productos falsificados; legitimidad; legalidad.

\footnotetext{
${ }^{1}$ Mestrado Profissional em Administração pela Universidade Estadual do Centro Oeste, Brasil (2018). Professor Visitante da Faculdade de Ciências Sociais e Aplicadas do Paraná.

2 Doutorado em Administração pela Universidade Positivo, Brasil (2017). Professor Adjunto B da Universidade Estadual do Centro-Oeste - UNICENTRO.

${ }^{3}$ Doutorado em Educação pela Universidade Federal do Paraná, Brasil (2010). Professor Titular da Universidade Estadual do Centro-Oeste - UNICENTRO.
} 


\section{Introdução}

A aquisição e comercialização de defensivos agrícolas envolve uma série de requisitos legais a serem atendidos, o que implica em um maior custo financeiro, além das questões burocráticas que permeiam o processo. As indústrias produtoras devem garantir o retorno das embalagens e promover toda uma estrutura de recebimento que possibilite o consumidor final fazer a entrega destes materiais. Os revendedores por sua vez, orientam os agricultores quanto a forma de consumo e devolução dos produtos, além de emitir nota fiscal com prazo de 12 meses a partir da data de aquisição para entrega das embalagens em local específico, estes dados são transmitidos e monitorados por agentes governamentais, que atendem aos requisitos legais formalizados.

Em decorrência de todo este processo este estudo tem como intuito analisar as questões de legitimidade e legalidade pertencente ao processo de aquisição e consumo de defensivos agrícolas, mas além disso a devolução de suas embalagens. No que tange as interrelações entre os membros que fazem parte deste processo, na defesa de seus interesses e busca de resultados. Ou seja, nesse caso, o modus operandi de trabalho, baseia-se em fatores que motivam e legitimam as ações de cada indivíduo ou grupo.

Além do mais, o conjunto de ações e discursos relacionados a aquisição, consumo e devolução das embalagens de defensivos agrícolas perpassa fatores sociais, práticas e todo aspecto de governança, seja ele, legal ou social (SIMON, 1999). Esse estudo, propõe analisar aspectos de legitimidade e legalidade em relação aos processos organizacionais no consumo de defensivos agrícolas ilegais ou também chamados de piratas, considerando que o modo de agir e reagir dos indivíduos estará relacionado a condições do grupo ao qual pertencem, no sentido de estrutura da legitimidade (ROSSONI, 2016).

Ao se discutir a legitimidade e legalidade, inicialmente trata-se as influencias legais e sociais, a construção de leis que muitas vezes são motivadas por estruturas e regras, dadas como entradas no processo de modificação, como também o impacto da lei no comportamento no mundo a fora, que geram saídas ou funções para um sistema (SILBEY, 2010). Logo, discussões do sistema legal em torno da aquisição de defensivos agrícolas demonstram uma preocupação social, ambiental e econômica. Logicamente, este sistema possui barreiras, e estas muitas vezes, impulsionam consumidores a buscar produtos alternativos, contrabandeados ou piratas. Destaca-se que o argumento central deste estudo 
presume que há legitimidade no consumo de defensivos contrabandeados ou falsificados por uma parcela dos consumidores deste nicho de mercado.

$\mathrm{Na}$ sequência, discute-se as dimensões da legitimidade (Scott, 2003), o modo que afetam, sendo, principalmente, caracterizado pela forma de aceitação, persuasão e convencimento em uma relação entre indivíduos ou órgãos. O confronto entre as ideias de Scott (2001), Dimaggio e Powell (1983) permite uma análise sobre o que impulsiona e possibilita que estruturas, políticas e as condições de vida em sociedade, sejam aceitas e legitimadas, no sentido de concordância voluntária ou involuntária com determinada situação. Sendo assim, nem sempre submissa a aceitação forçada ou imposta.

Ainda, não menos importante, os conceitos foram relacionados e aplicados em um modelo síntese que se propõe a observar as condições de aceitação, legalidade e legitimidade de padrões estabelecidos, demonstrando como se configuram os relacionamentos em seu sentido amplo, no entanto, primordial para generalização do estudo, como método adotado. E, finalmente.

\section{Aspectos Conceituais sobre Legitimidade e Legalidade}

Neste capítulo, serão abordados conceitos relacionados a legitimidade e legalidade. Os principais conceitos e definições que permeiam os tópicos acima citados, com intuito melhor de compreender a relação de aceitação e uso de defensivos piratas.

Para construção deste estudo, inicialmente, faz-se importante conceituar instituições e organizações, considerando que estas possuem conceitos complementares, enquanto que as organizações são técnico-racionais e trabalham em prol de um objetivo comum entre os indivíduos que dali fazem parte. As instituições têm um intuito maior, relacionado a percepção social, ou seja, sua relação com ambiente externo de modo que haja padrões de legitimidade e legalidade. "Instituições exibem propriedades estruturais mais permanentes nos sistemas sociais, o que pode associá-las à condições de resistência à mudança, especialmente se observadas num período de tempo curto, como a biografia do indivíduo" (GUARIDO FILHO, 2008, p. 20).

Conforme Scott (2001) existem três pilares que demonstram a influência sobre o comportamento social, que são as bases para legitimidade. Conforme quadro 1 . 
Quadro 1. Pilares de análise institucional.

\begin{tabular}{|c|c|c|c|}
\hline \multicolumn{4}{|c|}{ Pilar } \\
\hline & Regulativo & Normativo & Cognitivo-cultural \\
\hline Base de obediência & Utilidade & Obrigação Social & $\begin{array}{l}\text { Taken for gratedeness } \\
\text { Entendimentos } \\
\text { compartilhados }\end{array}$ \\
\hline Base de ordem & Regras regulativas & Expectativas normativas & Schemas constitutivos \\
\hline Mecanismos & Coercitiva & Normativa & Mimética \\
\hline Lógica & Instrumentalidade & Adequação & Ortodoxia \\
\hline Indicadores & $\begin{array}{l}\text { Regras } \\
\text { Leis } \\
\text { Sanções }\end{array}$ & $\begin{array}{l}\text { Certificação } \\
\text { Confiabilidade }\end{array}$ & $\begin{array}{l}\text { Crenças comuns } \\
\text { Lógicas de ação } \\
\text { compartilhadas }\end{array}$ \\
\hline $\begin{array}{ll}\text { Base } & \text { de } \\
\text { legitimidade }\end{array}$ & Legalmente sancionada & Moralmente governada & $\begin{array}{l}\text { Compreensível, reconhecível, } \\
\text { culturalmente amparada. }\end{array}$ \\
\hline
\end{tabular}

Fonte: Scott (2001, p. 52)

São compreendidas como composições de "[...] elementos cognitivo-culturais, normativos e regulativos que, juntamente com atividades e recursos associados, fornecem estabilidade e significado à vida social" (SCOTT, 2003, p. 48). O processo de desenvolvimento e legitimidade das ações ocorre a partir da particularização de situações que acontecem dentro da sociedade e que, no decorrer do tempo, são aceitas e objetivadas, que se tornam de algum modo habituais e são inquestionáveis e, ainda, concorrem a compartir os fatos e estes são aceitos, tornando-se arraigados aos processos (GUARIDO FILHO, 2008).

Em relação a organização, alguns autores fazem uma distinção entre ambiente técnico e ambiente institucional. O ambiente técnico é definido como o domínio no qual "[...] um produto ou serviço é trocado no mercado e as organizações são premiadas pelo controle eficiente e eficaz do processo de trabalho" (SCOTT, 2008). Já o ambiente institucional é caracterizado "[...] pela elaboração de normas e exigências a que as organizações se devem conformar se querem obter apoio e legitimidade do ambiente" (SCOTT, 2008).

Os pilares apresentados por Scott (2001) possuem forte influencia na análise institucional e de legitimidade, por isso, para o embasamento deste estudo faz necessário a utilização dos conceitos apresentados a partir dos fatores destacados em cada um dos pilares e é provável e evidente para instituições que buscam legitimidade (DIMAGGIO \& POWELL, 1991; 1983; MACHADO-DA-SILVA \& FONSECA, 1983).

Um dos fatores de destaque são os mecanismos apresentados por Scott (2001), que se subdivide em três categorias: coercitiva, mimética e normativa.

A categoria coercitiva representa aspectos regulativos, além das pressões formais e informais decorrentes de organizações que possuem maior poder, muitas vezes representam 
esse poder em virtude de serem detentoras de recursos. O mecanismo mimético ocorre a partir da reprodução de modelos utilizados em outras organizações que que demonstram ser bem sucedidos. Por fim, o mecanismo normativo é decorrente da profissionalização, métodos e procedimentos relacionado a cada campo organizacional (MEYER \& ROWAN, 1992; DIMAGGIO \& POWELL, 1983).

Os três mecanismos funcionam independentemente, mas ao mesmo tempo são complementares e afetam a todo tempo o ambiente institucional (Scott, 2001). Logo, quando se analisa determinado campo organizacional, é coerente avaliar os mecanismos, a fim de se reconhecer a base de legitimidade.

A legalidade está intrinsecamente, relacionada as leis e práticas culturais, ou comumente reconhecida como fonte de autoridade, leis e ações culturais (SILBEY, 2010). Notavelmente, o conceito de legalidade e legitimidade se aproximam devido a interesses específicos de instituições, no caso em análise, as leis que direcionam as formas de comercialização dos defensivos, regulam o mercado, de modo que, os padrões estabelecidos sejam aceitos e incorporados pela sociedade, sendo assim, legitimados.

A partir da legalidade, sugere-se estruturas tomadas como ideais. A reprodução social enquanto estrutura se ramifica em duas vertentes, a estrutura e os sistemas sociais. Enquanto a reprodução vista como ação resultante da reavaliação, que se recria, reinventa e se fundamenta, mas que ao mesmo tempo transparece pela capacidade de racionalização aos sistemas sociais, formados logicamente, por um conjunto de atores (GIDDENS, 2000). E ainda, o sistema social aquele formado por grupo de atores que possuem práticas sociais instituídas em um mesmo ambiente, que se repetem continuamente, sendo a estruturação a continuidade das ações e práticas, que envolvem regras, poder e significados (GIDDENS, $1989 ; 1978)$.

O conhecimento transcende um agente qualquer, mas personaliza e personifica um grupo de agentes, desta forma, argumenta-se que o conhecimento é recíproco e caracterizado a partir das trocas em situações também práticas. Sendo que, as trocas no sentido também de conhecimento refletem um conjunto de regras e padrões, consideradas propriedades estruturais (GIDDENS, 2000; COHEN, 1989). A legalidade pode gerar mudanças nas estruturas sociais, como também permite identificar se estruturas institucionalizadas derivam de ideais legais, a partir de princípios e políticas.

A legalidade, está relacionada a legitimidade legal, ou seja, há um entendimento e aceitação organizacional e social. No entanto, por vezes existe a manipulação das regras, 
como no caso dos defensivos piratas. Para tanto, busca-se compreender de que modo estão estruturadas as normas, regras e leis em relação ao consumo e utilização destes produtos, bem como aspectos de legitimidade que influenciam todo o processo de comercialização (GREENHOUSE, 2014).

\section{Metodologia}

Este estudo caracteriza-se como sendo de natureza descritiva porque se propõe em identificar, descrever e discutir fatores relacionados ao processo de investigação e fazer levantamentos buscando compreender o campo de estudo, ou seja, o processo da cadeia reversa das embalagens de agrotóxicos.

Deste modo, o estudo realizado configura-se como sendo de abordagem qualitativa que para Godoi (1995) não utiliza como objeto de estudo bases estatísticas nas análises porque o seu intuito é mais amplo. Ou seja, é na compreensão de fenômenos que o estudo se define conforme os focos de interesse. Somado a isso, esta abordagem preocupa-se com o processo e não com o resultado final.

Para tanto, o processo de coleta de dados ocorreu por meio de artigos, materiais e registros do setor, para atender o intuito da diversificação dos dados e o atendimento do objetivo principal. Ressaltando, que foram escolhidos como objeto de estudo por serem o elo fundamental do processo.

Os principais eixos da pesquisa para as análises abordaram:

I -Perfil de consumo: que compreende o papel do produtor, frequência de aquisição de defensivos e frequência de devolução;

II - Relações: visão sobre as parcerias, agências reguladoras e fiscalização;

III - Processo: visão sobre funcionamento do processo, vantagens e desvantagens e a questão de segurança e meio ambiente.

Os resultados encontram-se no item a seguir.

\section{A Legitimidade e Legalidade na Prática de Comercialização de Defensivos Piratas}

A comercialização de defensivos agrícolas ainda sofre críticas em relação a sua aceitação no controle de pragas, por ser um produto químico e de alto risco. Porém, seu consumo tem se multiplicado ao longo dos anos. "O aumento no consumo de agrotóxicos vem acompanhado do uso e descarte das embalagens vazias destes produtos" (GODECKE \& TOLEDO, 2015, p. 222). Os defensivos agrícolas ou agrotóxicos são caracterizados como 
substâncias que buscam proteger as plantas de condições naturais do ambiente, mas que podem interferir no seu desenvolvimento. Assim, possuem vários codinomes: agrotóxicos, defensivos, agroquímico, até mesmo veneno (VAZ, 2005). Envolvidos com esse tipo de produto existem muitos atores, desde indústria produtora, logística, distribuidores e produtores. Há, também, agências reguladoras, associações, organizações que dão suporte ou orientam e até mesmo fiscalizam e, mesmo exercendo diferentes atividades, todos desembocam em um objetivo final, a produção adequada de alimentos e produtos agrícolas. Mas, ao se tratar do ramo produtivo de defensivos, percebe-se que há grandes desafios que permeiam a rotina de produção e comercialização desses produtos.

O Brasil como um grande produtor agrícola e que necessita de um controle de pragas faz uso dos defensivos. Além de problemas como o uso inadequado e a falta de cuidado, tanto com o ambiente como com a saúde humana, tem trazido grandes riscos. A partir disso, algumas normas e condições legais são impostas pelo governo, que geram uma estrutura social, no que tange a utilização e retorno das embalagens, a fim de inibir a poluição, o uso inadequado, como também a reutilização das embalagens para comercialização de produtos falsificados (FARIAS, MINGOTI \& SPADOTTO, 2017).

Existe uma estatística, de acordo com Instituto Nacional de Processamento de Embalagens Vazias (INPEV, 2016), que há uma eficiência no processo de retorno das embalagens em 95\%, ou seja, acredita-se que do potencial de consumo do período, os $100 \%$ dos produtos utilizados, destes $95 \%$ suas embalagens retornam a indústria e são reaproveitados. Porém, nesse caso, não foram considerados os produtos falsificados, logo essa porcentagem de eficiência é errônea e não caracteriza a realidade, considerando que há grande quantidade de produtos falsificados e contrabandeados que são comercializados no país.

Sendo que, de acordo com Sindiveg (2016), “[...] estudos atuais apontam que o contrabando pode atingir até $20 \%$ das vendas de defensivos agrícolas no Brasil”. Mas toda a comercialização desse tipo de produto é fiscalizada e regulamentada, a Lei $n^{\circ} 7.802$, de 11 de julho de 1989, regulamentada pelo Decreto $n^{\circ} 4.074$, de 4 de janeiro de 2002, que disciplina a produção, a comercialização e uso de agrotóxicos (BRASIL, 2002).

Uma forma de tentar inibir e regulamentar o uso desses produtos é documentado através do código de conduta internacional da distribuição e uso de pesticidas, o qual regulamenta a responsabilidade de produção, comercialização e recomendações de uso (DORFMAN, FRANÇA \& SOARES, 2014). O contrabando é caracterizado como ilegal e, 
juntamente a essa prática, são caracterizados outros crimes de acordo com a Organização Mundial do Comércio (OMC) (Convenção de Roterdã, 2009).

O contrabando é visto como a entrada e saída de produtos de um país de forma ilegal, que não respeita as normas e regras. Ou seja, vai contra os mecanismos coercitivo, mimético e normativo dos meios de comercialização legais. Mas e por que muitas vezes o olhar se volta para o objeto de contrabando e não diretamente para a prática ou processos. Pois, muitas vezes é a partir da prática que os atos ditos como ilícitos ocorrem. A comercialização vista de modo adequado por parte da sociedade, ou seja, legítima quando se trata de defensivos agrícolas, é aquela que respeita as normas e imposições legais de produção, comercialização e uso do produto. Mas, muitas vezes não são conhecidas as características dos defensivos tidos como piratas ou ilegais. Esses produtos possuem alterações químicas em sua composição, como também os registros adequados nos órgãos regulamentadores (EDELMAN, 2016).

Os defensivos piratas são vistos como contrabandeados ou falsificados. Os contrabandeados não incorporam a base legal, então, neste caso não atende os aspectos isomórficos coercitivos, como também ignora as regras e padrões estabelecidos pela lei, assim a estrutura criada pela legalidade e legitimidade social, neste caso, acaba manipulada. Já os falsificados, possuem na sua composição alterações químicas diferente dos produtos chamados originais, logo as substâncias possuem, em alguns casos, até a anulação de sua eficácia, para tratamento das plantas, o que não significa ser isento de um potencial de agressividade com a saúde humana, animal ou do meio ambiente. Neste caso, também há um redirecionamento nos padrões legais pré-estabelecidos que geram uma estrutura de comercialização diferente do ideal proposto a partir da lei implantada (FARIAS, MINGOTI \& SPADOTTO, 2017).

O termo pirata, se dá pelo fato de que a palavra remete a cópia, ao plágio ou a infração. Então, caracteriza-se como um defensivo pirata, aquele que possui uma cópia ao produto padrão que incorpora os mecanismos em parâmetros coercitivos, miméticos e normativos. Logo, o pirata não incorpora nenhuma das características isomórficas anteriormente citadas, sendo que caracteriza-se como uma cópia que não obedece os padrões apropriados a determinado produto.

Com vistas a compreender as principais categorias analíticas desse estudo, presume-se a legitimidade, legalidade e os mecanismos destacados por Scott (2001). O nível de análise compreendido é interorganizacional, pois, trata-se de diversos atores que se relacionam em torno de um propósito comercial, podendo, assim, ser tratado como o campo de análise. 
Assim, a legitimidade é dada pela conformação com uma situação (ROSSONI, 2016). Enquanto, que a legalidade, se dá geralmente por meio de uma lei, regras e padrões implantados que geram uma estrutura de funcionamento em relação aos processos. Nesse caso, a validade nesse processo se dá por uma parcela dos usuários desse tipo de produto, sendo que como anteriormente citado aproximadamente $20 \%$ do mercado consumidor absorve os defensivos contrabandeados ou pirateados. Indica-se que a legitimidade, nesse caso, não é nítida, sendo que para tal deve haver validade, apropriados e obrigatórios para serem tomados como legítimos (ROSSONI, 2016). De modo geral, deve ser visto como parcial de regulação da vida social, das composições formais ou informais, das instituições e suas propriedades. São compreendidas como composições de "[...] elementos cognitivo-culturais, normativos e regulativos que, juntamente com atividades e recursos associados, fornecem estabilidade e significado à vida social" (SCOTT, 2001, p. 48).

A legitimidade, então, ocorre a partir das bases: regulatória, normativa e culturalcognitiva. A legitimidade regulatória segue leis, regras e normas. A normativa, ou também vista como sociopolítica, segue normas e valores impostos pela sociedade. E, culturalcognitiva, segue a perspectiva de ecologia populacional, ou seja, características e padrões identificados como necessários (RUEF; SCOTT,1998).

As relações de legitimidade muitas vezes podem ser vistas com a lente da teoria institucional, quando as normas, padrões, crenças e valores que condicionam e determinam nossa forma de pensar e agir, mas muito além disso, no momento em que há aceitação do processo e este passa a ser internalizado em suas práticas e legitimado, nesse momento configura-se a aceitação e se torna utilitária. Logicamente, quando se trata de defensivos ilegais, que vão contra a estrutura legal criada e implantada, a relação interoganizacional ocorre a partir dos relacionamentos entre diversos agentes que compõem a cadeia produtiva e que, de certo modo, utilizam ou comercializam esses produtos. Para gerar um processo legítimo, busca-se compreender as características isomórficas, que de certo modo, influenciam o desenvolvimento de estruturas legais (RUEF; SCOTT,1998).

O mecanismo coercitivo se configura no tocante a aquisição por parte do produtor quando se vê exposto há diversas situações que forçam e impulsionam a buscar produtos alternativos, no entanto, deixa de seguir a estrutura legal socialmente legitimada, para consumir produtos que fogem a esta estrutura, rompendo e manipulando os aspectos legais (GINOSAR, 2014). 
Já o mecanismo mimético que parte do pressuposto muitas vezes cultural, tem uma conotação da existência de discursos, percepções e significados baseados no processo de trabalho e performance desempenhada pelos diversos produtores, ou seja, seu modo de atuação corresponde, muitas vezes, ao modo de trabalho e produção caracterizado a partir de estruturas culturais e cotidianas àquele indivíduo.

Nesse caso, será possível averiguar as principais características que motivam a aquisição de produtos legais ou ilegais, bem como a percepção que os produtores possuem sobre essa opção e, também, os resultados gerados. Não apenas no que relaciona-se a produção em si, mas o que diferencia um produto do outro, suas características, agressividade com o meio ambiente e usuário do produto, além da aplicabilidade. Logo, verifica-se que o mecanismo mimético representa, além de tudo, a percepção sobre como as atitudes impactam a condição produtiva e quais resultados são alcançados. Para tanto, a condição cultural deveria ser esclarecedora quando se trata sobre a periculosidade dos materiais que são comercializados ilegalmente, pois afetam o consumidor final, o meio ambiente (animais, solo, ecossistema) e o agricultor (DORFMAN, 2014; GODECKE, 2015).

O mecanismo normativo, caracteriza-se a partir da profissionalização. Nesse caso, exclui-se o profissional habilitado para prescrever e aplicar o produto na lavoura, pois é dispensado no momento em que o agricultor rompe com a estrutura legal firmada, ou socialmente aceita.

Nesse caso, as alianças ocorrem por parte daqueles que contribuem para as ilegalidades em relação ao produto e sua venda. Mas, além disso, vai contra toda uma rede legal que possui atores como os agrônomos que emitem os receituários, os sindicatos e indústria agroquímica, as agências reguladoras da qualidade sanitária, os agentes de intervenção, como por exemplo, polícia ambiental, as agências reguladoras do controle de comercialização e, finalmente, os produtores (GREENHOUSE, 2014).

Quando se trata das alianças em um processo ilícito, há uma quebra em toda prática e nos relacionamentos, e os agentes buscam, por meio das alianças, acobertar e manter os vínculos de negociação. Portanto, os diferentes autores que fazem parte do processo de produção e comercialização de defensivos piratas possuem estratégias de cooperação, ressaltando as condições de relacionamentos estratégicos, bem como a formação de redes, para o estabelecimento de relações que tragam condições mais claras e objetivas no enfrentamento das dificuldades de mercado (GREENHOUSE, 2014). 
Notavelmente, cada abordagem possui um foco, econômica ou sociológica, ambas buscam diferentes resultados e possuem diferentes ações, no entanto, a abordagem da pesquisa em estratégia busca continuidade de desenvolvimento racional de métodos, modelos e ferramentas para que as inovações são incorporadas no comportamento organizacional.

A produção e comercialização de defensivos piratas ou ilegais exercem domínio, no sentido que, por meio do preço, da desburocratização no que se refere a aquisição dos produtos, diferença na legislação e as facilidades no acesso são as principais características que impulsionam esse comércio. Ora em momentos coercitivos, quando exime de obrigações, ora mimético e normativo quando as estratégias são formadas a partir de novas regras e um diferente posicionamento cultural (GINOSAR, 2014).

De acordo com Bulgacov (2007), as pesquisas de estratégia seguem três perspectivas distintas: o ambiente estratégico que visualiza aspectos relacionados as forças ambientais, posicionamento, relacionamentos ou agentes de interesse, com olhar analítico de empresa versus ambiente (mercado); já conteúdo estratégico busca, essencialmente, a vantagem competitiva, por meio de produtos e tecnologias no segmento de atuação; e processo estratégico que possui olhar nas configurações empresariais, de cultura, poder e mudança.

A configuração das estratégias no meio legal busca garantir o cumprimento das leis, relacionadas a utilização dos produtos e, ainda, garantir a sobrevivência humana e ambiental, de acordo com parâmetros vistos como coerentes, que ao mesmo tempo relaciona diversos órgãos e indivíduos formando, assim, a rede de comercialização legal de defensivos agrícolas. Mas, em que momento difere o funcionamento da rede de comercialização dos produtos vistos como piratas ou ilegais, certamente, dar-se-á em todo o seu desenrolar, pois, desde a sua produção, notam-se as incoerências com as diretrizes legais dos ingredientes químicos utilizados, bem como do seu processamento. E, posteriormente, a esse processo, ocorre a distribuição ou comercialização de modo restrito dada sua ilegalidade, mas que ao mesmo tempo exerce determinado poder sobre a sociedade, quando apresenta a possibilidade de uso de um produto com valor mais baixo, além de um processo de aquisição desburocratizado (DORFMAN, 2014).

Então, a produção e comercialização de defensivos agrícolas piratas, ocorre de modo ilegal, mas não deixa de possuir relacionamentos com diversos atores relacionados, sendo alguns centrais para o desenvolvimento de todo o processo. Provar que se tornou legítimo e que há aceitação, não é assim algo fácil de mensurar, constatado que ocorre de modo ilegal. Os possíveis sujeitos que financiam esse processo não são capazes de admitir tal prática, 
cientes das punições que poderão sofrer. Mas, adicionalmente, a legitimidade não ocorre somente pelo fato de que há uma parcela de aceitação, ao contrário, para que isso realmente ocorra deve-se ter uma percepção geral pela sociedade de que as ações daquela organização serão instituídas e legitimadas (SUCHMAN, 1995).

Para tanto, a legalidade e o sistema social regula as práticas e, muitas vezes, determina princípios estruturais enraizados para que haja legitimidade. Na figura 1, apresenta-se um modelo síntese sobre a legitimidade e legalidade na comercialização de defensivos piratas. Inicialmente, são apontadas três influências sobre a aceitação no processo de comercialização, sendo: regulatória, normativa, cultural-cognitiva. A partir destas influências, busca-se compreender o modo que cada uma impulsiona a aceitação dos produtos falsificados por parte dos consumidores.

Figura 1. A legitimidade na comercialização de defensivos piratas

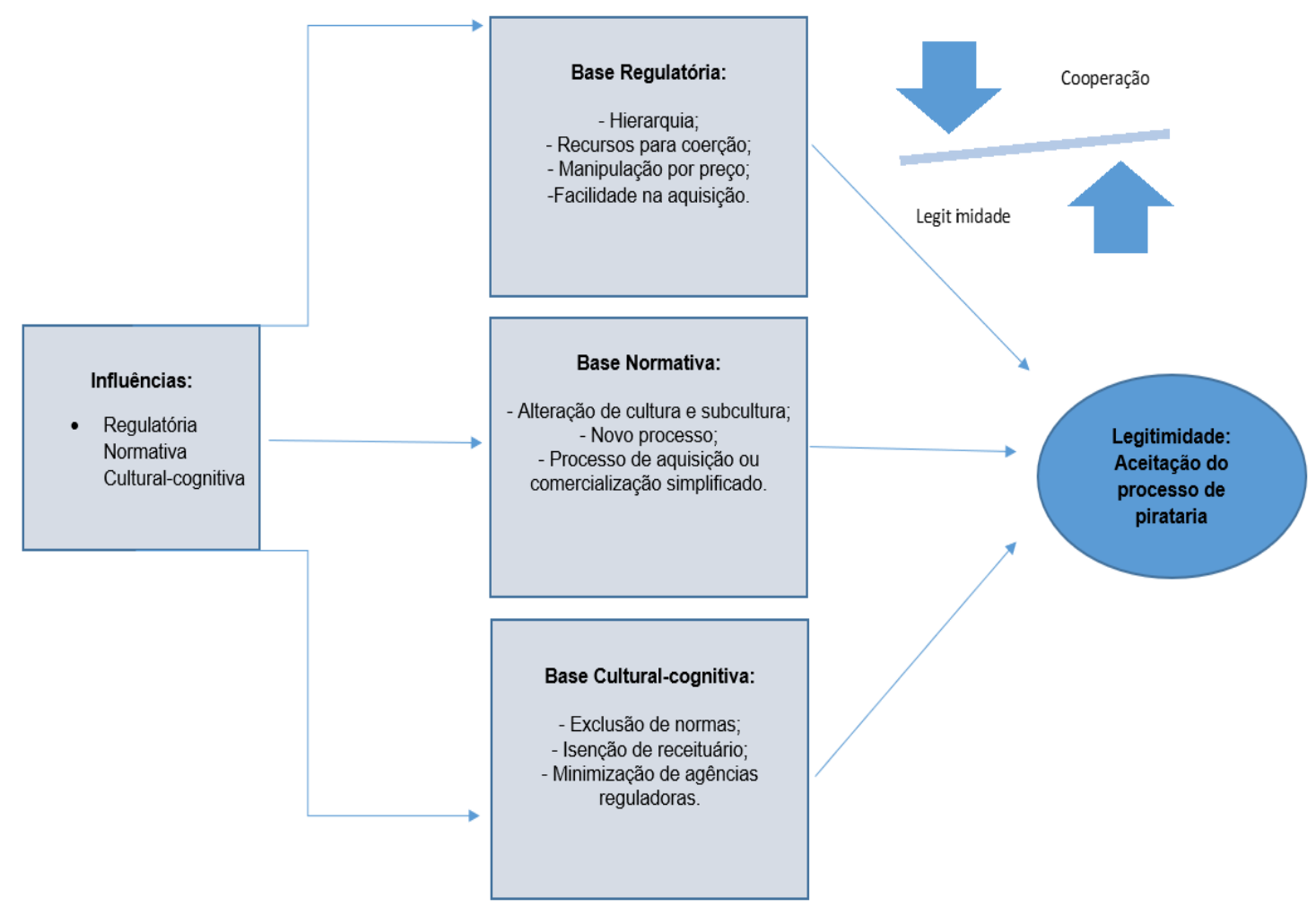

Fonte: elaboração própria (2018)

Inicialmente, são apontadas três influências sobre a aceitação no processo de comercialização, sendo: regulatória, normativa, cultural-cognitiva. A partir destas influências, busca-se compreender o modo que cada uma impulsiona a aceitação dos produtos falsificados por parte dos consumidores (GODECKE, 2015). 
Ao observar a condição regulatória, pode-se notar que, inicialmente, há certa hierarquia, no sentido de que existem atores que detém de determinado poder sobre as negociações, caracterizadas, principalmente, em relação a entrada desses produtos, bem como sua comercialização, pois a maior parte dos defensivos piratas são contrabandeados. Logo, nesse sentido, avalia-se o aspecto hierárquico relacionado aos indivíduos que tem domínio sobre as práticas de comercialização dos produtos. No que tange recursos para coerção, a facilidade para aquisição, preço acessível e toda desburocratização, são características vistas como influenciadoras sobre a aceitação do produto pelo público consumidor (DORFMAN, 2014).

No aspecto normativo, a questão cultural referente aos padrões legais estabelecidos para a compra dos defensivos se mostra, muitas vezes, burocrática, com intuito de atender a todos os requisitos legais impostos, como forma de garantia da qualidade do produto, como também em conhecer aqueles que fazem uso desse material, além de garantir que haja o retorno adequado das embalagens, aqui considerando a logística reversa embutida no processo. Sobretudo, indica-se a subcultura relacionada a desburocratização e acesso ao produto ilegal, falsificado, de maneira facilitada (GREENHOUSE, 2014).

Por fim, discute-se relação cultural cognitiva, nesse aspecto, evidencia-se a exclusão de normas estabelecidas por agências reguladoras, como a isenção de receituários, que possuem o intuito de garantir a qualidade e quantidade dos produtos utilizados pelos produtores. Logo, toda desburocratização do processo no sentido de facilidades ao acesso aos produtos e a relação de preços baixos impulsionam o consumo e aceitação por grande parte dos produtores, gerando a cooperação entre todos os atores envolvidos nas práticas de comercialização e consumo de tais produtos.

\section{Considerações Finais}

Esse estudo teve como propósito inicial elucidar questionamentos acerca dos aspectos de legitimidade e legalidade no consumo de defensivos piratas, no que tange o processo de produção e comercialização. Para construir uma ponte entre os conceitos de legitimidade e legalidade, baseados nos mecanismos coercitivo, mimético e normativo, como base para a legitimação, buscou-se então aproximar esses aspectos como influenciadores no desenvolvimento da rotina dentro da rede de comercialização dos defensivos.

A estrutura social criada a partir da legalidade gera uma legitimidade no consumo dos defensivos, de acordo com estatísticas do setor $80 \%$ dos consumidores fazem parte desta 
estrutura, no entanto, os outros $20 \%$ estão manipulando os padrões e leis estabelecidos. Pelo fato do sigilo advindo dos aspectos coercitivos sob o caráter manipulador das relações. Ou seja, em tratando-se de produtos ilegais, contrabandeados, que não respeitam condições legais e de segurança, em detrimento de suas alterações químicas e ciente do perigo e das possíveis causas desfavoráveis ao meio ambiente e também a saúde humana e animal, permite-se dizer que os agentes envolvidos nesse processo sofrem estilos de dominação e governança baseado nos conflitos gerados a partir da arriscada prática que vivem.

No modelo criado, nota-se, em resumo, que as bases de governança e legitimidade influenciam de modo diferente toda a ação da rede e que se torna legítimo para os envolvidos a partir do momento que internalizam aquelas práticas e já não mais as questionam. Ou seja, para os envolvidos no processo é correto o consumo dos produtos ilegais, ou também chamados piratas, mesmo que não atendam a requisitos legais e, sobretudo, todos aqueles que de certo modo estão envolvidos não internalizaram os padrões de comercialização, utilização e retorno das embalagens, bem como a importância dos aspectos legais, relacionados a estes produtos.

\section{Referências}

BRASIL. Decreto $n^{\circ} 4.074$, de 4 de janeiro de 2002. Regulamenta a Lei $n^{\circ} 7.802$, de 11 de julho de 1989, que dispõe sobre a pesquisa, a experimentação, a produção, a embalagem e rotulagem, o transporte, o armazenamento, a comercialização, a propaganda comercial, a utilização, a importação, a exportação, o destino final dos resíduos e embalagens, o registro, a classificação, o controle, a inspeção e a fiscalização de agrotóxicos, seus componentes e afins, e dá outras providências. Base da Legislação Federal do Brasil, Brasília, 2002. Recuperado de: http://www.planalto.gov.br/ccivil_03/ Acesso em 25 de março de 2018.

Bulgacov, S.; Souza, Q. R.; Prohmann, J. I.; Coser, C.; Baraniuk. J. A pesquisa em estratégia. In: Bulgacov, S.; Souza, Q. R.; Prohmann, J. I.; Coser, C.; Baraniuk. J. (2007) Administração estratégica: teoria e prática. São Paulo: Atlas, p. 132-163.

Carvalho, C. A.; Vieira, M. M. F.; Goulart, S. (2005) A trajetória conservadora da teoria institucional. Revista de Administração Pública - RAP, Rio de Janeiro, v. 39, n. 4, p, 849-874, Jul./Ago.

CONVENÇÃO DE ROTEDÃ. Sobre o procedimento de consentimento prévio informado aplicado a certos agrotóxicos e substâncias químicas perigosas objeto de comércio internacional. Brasília, 2009. Recuperado de: http://www.mma.gov.br/estruturas/smcq_seguranca/_arquivos/roterd_texto_143.pdf Acesso em 25 de março de 2018.

Dimaggio, P. J.; Powell, W. W. (1983) The iron cage revisited: institutional isomorphism and collective rationality in organizational felds. American Sociological Review, v. 48, n. 2 , p. 147-60. 
Dimaggio, P.; Powell, W. W. (2007) Jaula de ferro revisitada: isomorfismo institucional e racionalidade coletiva nos campos organizacionais. In: CALDAS, Miguel P.; BERTERO, Carlos O. (Coord.) Teorias das Organizações. São Paulo: Atlas.

Dorfman, A.; França, A. B. C.; Soares, G. O. (2014) Marcos legais e redes de contrabando de agrotóxicos: análise escalar a partir da fronteira Brasil-Uruguai.Terr@Plural, Ponta Grossa, v.8, n.1, p. 37-53, jan./jun.

Edelman, L. B. (2016). Working Law. Chicago: The University of Chicago Press

Godecke, M. V.; Toledo, E. R. M. S. (2015) Logística reversa de embalagens de agrotóxicos: estudo do caso de pelotas/RS. Revista Meio Ambiente e Sustentabilidade, v..9, n.4, jul - dez.

Ginosar, A. (2014) Public-Interest Institutionalism: A Positive Perspective on Regulation. Administration \& Society. April 46: 301-317. doi:10.1177/0095399712453926

Greenhouse, C. J. (2014) Unexpected properties: Strathern on the relation of law and culture», Theory, Culture \& Society, vol.31, no 2-3, p.167-184.. 31: 167.

Guarido, E. R., Filho. (2008) A construção da teoria institucional nos estudos organizacionais no Brasil: o período 1993-2007. 299 f. Tese (Doutorado em Administração) - Universidade Federal do Paraná, Curitiba, PR, Brasil.

INPEV Instituto Nacional de Processamento de Embalagens Vazias. (2016). Manejo das embalagens vazias no campo. Recuperado de: http://www.inpev.org.br/logisticareversa/manejo-das-embalagens-vazias-no-campo. Acesso em 25 de março de 2018.

Machado-Da-Silva, C. L.; Fonseca, V. S.; Crubellate, J. M. (2005) Unlocking the institutionalization process: insights for an institutionalizing approach. Brazilian Administration Review, v. 2, n. 1, p. 1-20.

RossonI, L. (2016) O que é legitimidade Organizacional? $O \& S$, Salvador, v. 23, n. 76, p. 110129, Jan./Mar.

Ruef, M.; Scott, W. R. (1998) A multidimensional model of organizational legitimacy: hospital survival in changing institutional environments. Administrative Science Quarterly, v. 43, n. 4, p. 877-904.

Scott, W. R. (2003). Institutional carriers: reviewing modes of transporting ideas over time and space and considering their consequences. Industrial and Corporate Change, v. 12, n. 4, p. 879-894.

Scott, W. R. (2008) Institutions and organizations: ideas and interests. (3rd ed.). Thousand Oaks: Sage.

Selznick, P. (1948). Foundations of the theory of organization. American Sociological Review, v. 13, n. 1, p. 25-35.

SINDIVEG. Sindicato Nacional da Indústria de Produtos para Defesa Vegetal Balanço 2015 - Setor de agroquímicos confirma queda de vendas. Recuperado: http://www.sindiveg.org.br/docs/balanco-2015.pdf Acesso em 25 de março de 2018.

Suchman, M. C. (1995). Managing legitimacy: strategic and institutional approaches. Academy of Management Review, v. 20, n. 3, p. 571-610.

Vaz, P. A. B. (2005). Crimes de agrotóxicos. Revista de Doutrina da $4^{a}$ Região, n. 8, 16 set.

\section{Recebido em 02/05/2019 - Aprovado em 05/07/2019.}

